\title{
DIREITO À VIDA E AO ABORTO: UMA ANÁLISE PELA DEMOCRATIZAÇÃO EFETIVA DOS DIREITOS DA MULHER BRASILEIRA
}

\author{
RIGHT TO LIFE AND ABORTION: AN ANALYSIS FOR THE EFFECTIVE \\ DEMOCRATIZATION OF BRAZILIAN WOMEN'S RIGHTS
}

\author{
Fernanda Caroline Alves de Mattos ${ }^{1}$ \\ Renato Bernardi ${ }^{2}$
}

\begin{abstract}
RESUMO: A presente pesquisa tem por objetivo desenvolver uma relação entre a descriminalização do aborto e a efetivação da democracia, como instrumento jurídico, político e social de proteção aos direitos femininos. Para isso, foram abordados os direitos da personalidade, em especial o direito à vida da mulher como forma de perceber a necessidade de sua proteção. Em seguida, buscou-se compreender a construção social sobre uma maternidade compulsória, que fundamenta a violação à vida e à autonomia femininas. Posteriormente, desenvolveu-se a análise e o argumento de que o não reconhecimento das diferentes necessidades dos grupos, nesse caso o grupo social "mulheres", em cada vivência é uma forma de violar a democracia. Para tanto, foi utilizado o método de abordagem dedutivo com suporte nos métodos bibliográfico e documental de procedimento, tomando como referencial teórico feminista a perspectiva de Butler, Flávia Biroli e de uma democracia pensada nas diferentes opressões de Chantal Mouffe. Dessa forma, ao concluir este trabalho, observamos que, o reconhecimento das necessidades subjetivas é fundamento para descriminalização da interrupção voluntária da gestação como meio para mulheres exercerem seus direitos em uma realidade verdadeiramente democrática.
\end{abstract}

PALAVRAS-CHAVE: Democracia; Direitos da personalidade; Gênero; Interrupção da gravidez.

ABSTRACT: This research aims to develop a relationship between the decriminalization of abortion and the effectiveness of democracy, as a legal, political and social instrument to protect women's rights. For this, the rights of personality were approached, especially women's right to life, as a way to understand the need for its protection. Next, we tried to understand the social construction of a compulsory maternity, which is the basis for the violation of women's life and autonomy. Subsequently, we developed the analysis and the argument that the nonrecognition of the different needs of groups, in this case the social group "women", in each experience is a way to violate democracy. To do so, the deductive approach was used, supported by the bibliographic and documental methods of procedure, taking as feminist

\footnotetext{
${ }^{1}$ Mestranda em Ciência Jurídica pela Universidade Estadual do Norte do Paraná - UENP, Bolsista pela CAPES. Graduada em Direito pela Universidade Tiradentes - UNIT/SE. Participante do grupo de pesquisa Intervenção do Estado na vida das pessoas (INTERVEPES-UENP) e do Grupo de pesquisa Direito e sexualidade (UFBA), ambos do diretório CNPq.

2 Doutor em Direito do Estado (sub-área Direito Tributário) - PUC-SP. Professor efetivo dos cursos de Bacharelado, Mestrado e Doutorado, Membro da Comissão Executiva do Colegiado do Curso de Graduação e da Comissão de Coordenação do Programa de Mestrado e Doutorado em Ciência Jurídica, todos do Curso de Direito do CCSA - UENP, Campus de Jacarezinho/PR. Coordenador Pedagógico do PROJURIS Estudos Jurídicos Ltda. Procurador do Estado de São Paulo.
} 
theoretical reference the perspective of Butler, Flávia Biroli, and a democracy thought of the different oppressions of Chantal Mouffe. Thus, in concluding this work, we observe that the recognition of subjective needs is the foundation for decriminalizing the voluntary interruption of pregnancy as a means for women to exercise their rights in a truly democratic reality.

KEY WORDS: Democracy; Personal rights; Gender; Pregnancy termination.

\section{INTRODUÇÃO}

O presente artigo tem por objetivo abordar a temática do direito à vida, relacionada ao aborto, pensando acerca da proteção deste direito à mulher, de forma digna, como ferramenta de efetivação da democracia. Democracia aqui sendo considerada como uma promessa de busca pela igualdade dentro do Estado Democrático de Direito. Uma promessa porque contém radicalidade que desequilibra horizontes estáveis de expectativas, transgrede o possível e o conhecido e vai além do que se prevê, não sendo posse de alguns, mas sim de todos (CHUEIRI, 2013, p. 35). Uma promessa prevista em texto constitucional como obrigação e que deve servir bússola para as lutas e posicionamentos jurídicos brasileiros, atingindo a todos, inclusive as mulheres e suas necessidades.

Tal temática se justifica em razão da crescente continuidade dos casos de aborto no Brasil, ademais da posição vulnerável feminina no que se refere direito ao próprio corpo e do exercício da autonomia feminina em uma sociedade cisheteropatriarcal e desigual de gênero. Nesse sentido, temos como debate a seguinte questão: não seria a descriminalização do aborto um meio de efetivação dos direitos da personalidade feminina e atenção a uma justiça de gênero?

Em um primeiro momento, importa apontar o que são os direitos da personalidade, qual sua importância para o ordenamento e para a vivência dos indivíduos e, nesse aspecto, em que ponto se encontra o direito à vida, com um foco específico sobre o direito a viver dignamente, com foco nas mulheres.

Em seguida, busca-se discutir as determinações sociais sobre o papel da mulher enquanto um corpo limitado, a ser impulsionado de forma natural à maternidade e as demais cobranças e limitações impostas em razão do seu gênero. Para, a partir disso, reconhecer como o aborto enquanto crime é uma é uma limitação, uma restrição de direitos, um controle rígido do corpo das mulheres; é uma postura 
de manutenção de uma desigualdade corroborada na violação do próprio direito à vida da mulher.

Em um terceiro momento, propõe-se analisar de que forma, diante da construção democrática estatal no Brasil se faz necessária uma política de reconhecimento de subjetividades para abraçar as diferentes necessidades da mulher como indivíduo e como sujeito de direitos. Dessa forma, ao longo do artigo analisamos e propomos esse reconhecimento a partir da descriminalização da interrupção voluntária da gravidez como ferramenta de constatação da autonomia e da liberdade feminina sobre o próprio corpo, e assim, uma efetivação real do princípio democrático da dignidade humana.

Para tanto, foi realizada pesquisa por meio do método dedutivo de abordagem, passando da premissa geral de que o reconhecimento de direitos diante das diferenças é parte da luta pela desigualdade de gênero e pela efetivação da democracia, para a premissa menor que os direitos à autonomia e à vida digna poderão ser respeitados, em uma perspectiva democrática, a partir da descriminalização do aborto. Utilizamos assim, fontes através de pesquisa bibliográfica e documental sobre o tema, tendo como base teórica principal uma perspectiva feminista.

\section{DIREITO À VIDA COMO DIREITO DA PERSONALIDADE NUMA PERSPECTIVA DE GÊNERO}

Em relação ao direito à vida, é importante apontar seu posicionamento enquanto direito da personalidade dos indivíduos e também sua perspectiva enquanto direito à vida nas conjecturas generificadas socialmente. Uma vez que socialmente há uma estrutura que forma e determina o gênero.

Nesse sentido, pensar sobre o indivíduo mulher dentro do estudo dos direitos da personalidade se faz necessário, já que, o "gênero pode ser visto fundamentalmente como uma questão de inclusão a nível social, como um processo que historiciza corpos reprodutivos" (CONNELL, 2014, p. 23), e em se tratando do 
reconhecimento de direitos, essa especificidade sobre a realidade feminina é parte de uma valoração mais completa do tema.

Inicialmente, é importante indicar o que são os direitos da personalidade e como o direito à vida se encaixa nesse grupo. De acordo com Carlos Alberto Bittar, eles são:

[...] reconhecidos à pessoa humana tomada em si mesma e em suas projeções na sociedade, previstos no ordenamento jurídico [em] defesa de valores inatos no homem, como a vida, a higidez física, a intimidade, o segredo, o respeito, a honra, a intelectualidade e outros tantos. (BITTAR, 2015, p. 29)

Dessa forma, a principal característica diante da abrangência dada aos direitos da personalidade é que são eles intrínsecos a existência humana, estão naturalmente vinculados a nascer enquanto humano, sendo, portanto, pertencentes a todo ser nascido vivo. Sua existência vem do que a vivência social gera, independendo de estarem ou não juridicamente delimitados, mas tendo sua previsão como forma de defesa na prática.

A partir disso, eles são conhecidos em outras perspectivas enquanto direitos fundamentais e também como direitos humanos. Enquanto no primeiro ângulo eles assim são chamados em relação ao reconhecimento deles no ordenamento jurídico positivo de um Estado, no segundo se trata do enfoque dado a eles no Direito Internacional. Porém, as diversas nomenclaturas não tiram da vista a necessidade de proteção e de acessibilidade aos direitos para além de sua positivação, sendo necessário o desenvolvimento de uma consciência dos indivíduos acerca dos seus direitos (BITTAR, 2015, p. 32).

A respeito da proteção, por exemplo, se observa sua inevitabilidade, uma vez que sendo direitos dos indivíduos e formados a partir de sua existência, a proteção deles pelo Estado é parte da própria reafirmação da dignidade humana. Nesse sentido:

la dignidad humana se deduce la existencia de un derecho al libre desenvolvimiento de la personalidad, que a su vez ha de considerarse como la matriz generadora de los derechos de la personalidad. Éstos son derechos del actuar de la persona, que, como ya hemos señalado, merecen y obtienen (en mayor o menor medida, y prescindiendo ahora 
de su eficacia real) reconocimiento y protección del mundo jurídico, en particular a través de su constitucionalización (MARTíNEZ; BENDAHÁN, 2006 p.187-188) ${ }^{3}$.

Assim, a proteção dos direitos da personalidade se traduz em ferramenta de reconhecimento da dignidade da pessoa humana. No entanto, conforme apontado antes, é preciso também garantir acessibilidade a esses direitos por meio do esclarecimento social deles, ou seja, do empoderamento e da consciência dos indivíduos de que são sujeitos desses direitos e os possuem para exercício. Uma vez que, a capacidade de poder rogar por eles é parte da condição de ser humano, já que todos os direitos da personalidade estão relacionados à vida do indivíduo, isto é, referem-se à pessoa em si e a sua posição nas relações sociais com os demais indivíduos e em suas projeções sociais (BITTAR, 2015, p. 49), cabendo a cada um lutar por eles em caso de não reconhecimento estatal.

Após essas considerações, vale exemplificar de que forma podemos reconhecê-los e dividi-los para uma melhor compreensão das áreas em que expressam na vida humana. Eles podem assim ser divididos em: direitos ao corpo, direitos psíquicos e direitos morais (BITTAR, 2015, p. 111) ${ }^{4}$, englobando assim aspectos subjetivos, de relações privadas e de relações públicas vivenciadas pelo ser humano.

Dentro desses grupos, cumpre dar destaque ao direito à vida para o desenvolvimento do presente trabalho. Assim sendo, o direito à vida é aquele que por excelência dá vazão a todos os demais direitos da personalidade, uma vez que, nascendo vivo, o indivíduo estará dotado de todos os outros direitos que dele

\footnotetext{
${ }^{3}$ A dignidade humana implica a existência de um direito ao livre desenvolvimento da personalidade, que por sua vez deve ser considerado como a matriz geradora dos direitos da personalidade. São direitos de ação da pessoa, que, como já assinalamos, merecem e obtêm (em maior ou menor grau, e agora desconsiderando a sua real eficácia) reconhecimento e proteção do mundo jurídico, particularmente através da sua constitucionalização (tradução nossa).

${ }^{4}$ Em relação a essa divisão, o autor optou por trabalhar alguns dos tipos de direitos da personalidade não esgotando o assunto - dentro da classificação que adotou. Do corpo ele entendeu enquanto: direito a vida, direito a integridade física, direito ao corpo, direitos a partes separadas do corpo, direito ao cadáver, direito à imagem - no sentindo de uso e não de moralidade relacionada a ela - e direito a voz. Dos psíquicos: direito à liberdade (locomoção, religiosa, expressão e etc.), intimidade (até para pessoas públicas haverão certos limites), integridade psíquica e direito ao segredo. Dos morais: direito à identidade, direito à honra (abrangendo reputação e consciência subjetiva da própria dignidade), direito ao respeito (proteção a ofensas no meio social), e às criações intelectuais (abrangendo a parte moral da criação e a patrimonial do lucro da produção).
} 
dependem. Assim, o que se observa dentro das Constituições como a brasileira é que, na Carta Magna, ficou "proclamado como imperativo fundamental da convivência social a proteção a vida, incluída entre os direitos essenciais e mais elementares da pessoa" (BITTAR, 2015, p. 120). Dessa forma, vê-se como o direito à vida é por si só complexo e amplo, englobando os demais direitos pertencentes ao grupo dos direitos ao corpo. Já que irá:

[...] abranger uma série de matérias[...]: a vida; a condição jurídica do nascituro; o direito à velhice; a eutanásia; o direito ao gene e ao óvulo; a gravidez extra-uterina; a inseminação artificial; o transexualismo, homossexualismo e intersexualismo; o planejamento familiar (esterilização); o aborto; a cirurgia plástica estética e corretiva; transplante de órgãos; a prorrogação artificial da vida; a reanimação; outros (ROBERTO, 2004, p. 350).

Isto posto, considerando que o reconhecimento dos direitos da personalidade é parte precípua da dignidade humana e o direito à vida é abrangente de outros direitos e complexo em sua existência, é possível confirmar que sua consideração nas diversas searas é parte indissociável da promoção da vida digna ao indivíduo. E, dessa forma, "[...] a vida merece prioridade na proteção como forma de acolher a dignidade humana em sua forma mais completa" (ROBERTO, 2004, p. 352).

A partir dessas informações é possível fazer alguns questionamentos: quais são as vidas que realmente importam? Existem diferenças nas considerações do direito à vida dentro da sociedade? Com o objetivo de trabalhar essas indagações e prosseguindo no objetivo de pesquisa, faz-se necessário compreender de que forma as diferenças de gênero correspondem enquanto marcadores de diferença na determinação e reconhecimento do direito à vida para as mulheres.

Em relação ao direito à vida feminino, é importante ressaltar que o sujeito mulher - que não é homogêneo em essência, tampouco é estável (BUTLER, 2019, p. 18) - se encontra em uma perspectiva de minoria enquanto grupo social. Por isso, é preciso o cuidado diferenciado ao direito das mulheres, aqui em especial o direito à vida. Essa necessidade se justifica na medida em que a mera formalidade da consideração do direito à vida no ordenamento em sua disposição generalizada não consegue atingir a todos de forma equânime, pois: 
[...] a igualdade formal, propiciada pela linguagem dos direitos não se converte em acesso igualitário ao Estado de Direito ou à aplicação imparcial das leis e dos direitos. Assim, é possível ter-se direitos, mas não se possuir recursos suficientes para exigir sua implementação (SILVA, 2010, p. 134).

Esses recursos não são apenas relacionados ao quesito financeiro, mas também recursos no que se refere a espaço e poder de fala nos espaços públicos. Disso decorre que, em razão de espaço de fala, a mulher sofre opressão social baseada no sistema patriarcal que a exclui em razão do gênero (ademais quaisquer outros polos de opressão sofridos na individualidade de cada uma) ${ }^{5}$. Essa opressão em razão do gênero se constitui dentro das determinações dicotômicas vinculadas à uma existência feminina válida, isto é, são determinados espaços e formas de agir ao que é feminino, o que por si só já gera uma exclusão.

Essa dicotomia se baseia na existência de um espaço público e um privado, na verdade uma polarização em que, no segundo, são formados estereótipos de gênero que são desvantajosos para a mulher, nos quais se atribuem papéis de dedicação à vida doméstica e à família. Esses papéis estimulam a ideia de domesticidade feminina como algo natural e como um valor, o qual determina que qualquer outro comportamento distinto será considerado como desvio (MIGUEL, BIROLI, 2014, p. 32).

Estas expectativas valoradas abrem margem para a violência contra as mulheres que "desviam", uma vez que "a garantia de privacidade para o domínio familiar e doméstico foi vista [...] como uma das ferramentas de manutenção da dominação masculina" (MIGUEL, BIROLI, 2014, p. 32). A partir disso o que se tem é que se a mulher que deve ser "domesticada" se desvia, a primeira colocação vai ser o exercício do controle sobre ela, o qual poderá se dar através da violência física, por exemplo, colocando em xeque a integridade física de seu corpo e até mesmo sua própria vida. Mas esse controle vai além da violência, se baseando na tentativa de uma disciplina que marca, dirige e sujeita quem está a passar por ele, para que o

${ }^{5}$ A existência de diferentes polos de opressão aqui falados faz referência a consideração do nó existente entre discriminação de gênero, raça e classe concebido por Heleieth Saffioti (1989, p. 16), onde cada uma dessas opressões não andará sozinha dentro da realidade de exclusão brasileira. 
corpo desse sujeito seja útil aos interesses de quem estiver hierarquicamente superior nas relações de poder (FOUCAULT, 1987, p. 29).

Esse controle se observa dentro da possibilidade viver e dispor do seu corpo livremente, que não ocorre para a mulher, como a exemplo do exercício livre do aborto conforme se verá, que parte de uma defesa social suprema sobre a vida do feto em detrimento da proteção da vida da mulher, diante de uma visão conservadora que representa uma sociedade e um Estado despreocupados com as causas femininas (SANTIAGO, 2017, p. 127).

Assim, quando se observa o direito à vida em uma perspectiva de gênero é necessário considerar os controles, limitações e violações impostos sobre ele quando se trata do sujeito mulher. Pois, ainda que seja a vida um direito intrínseco a ser humano, quando se trata da realidade feminina baseada na desigualdade de gênero, sua vida e sua autonomia se encontram assim limitadas por uma realidade machista e cisheteropatriarcal.

\section{O ABORTO, CONTROLE SOCIAL E SAÚDE DA MULHER}

As proteções ao direito à vida se presumem em diversas fontes no ordenamento brasileiro. Sua primeira parcela está prevista no próprio texto constitucional no art. $5^{\circ}$, inciso XLVII, alínea "a", onde é proibida a pena de morte no Brasil, salvo em caso de guerra declarada; bem como em outros instrumentos jurídicos com diferentes estatutos, como os previstos no Código Civil (artigos $1^{\circ}$ e $2^{\circ}$ ) e Penal (artigos 124, 126 e 128), na medida de proteção ao nascituro.

Traçando um caminho sobre o aborto e o controle sobre o direito à vida da mulher, o que se observa é que este é produzido e reproduzido pela sociedade e pelo ordenamento jurídico também, em especial, quando se coloca em pauta a desconsideração do direito à autonomia e à liberdade de escolha femininos quando se trata de interrupção de gestação. O que mormente poderá ser considerado também enquanto uma desconsideração do seu direito à vida.

No que concerne ao aborto enquanto fenômeno social é importante ressaltar os construtos sociais que determinaram o incômodo e posterior criminalização do ato. Inicialmente, destaca-se que se desenvolveu uma cultura de um amor materno 
natural, onde a mulher estaria prioritariamente desenvolvida enquanto sujeito para ser mãe. Conforme afirma Batinder:

A cultura não passa de um epifenômeno. Aos seus olhos, a maternidade e o amor que a acompanha estariam inscritos desde toda a eternidade na natureza feminina. Desse ponto de vista, uma mulher é feita para ser mãe, e mais, uma boa mãe. Toda exceção à norma será necessariamente analisada em termos de exceções patológicas. A mãe indiferente é um desafio lançado à natureza, a anormal por excelência (BATINDER, 1985, p. 09).

Dessa forma, a existência de uma mulher que se direcione na escolha pela interrupção da gravidez estaria sendo não só anormal, mas completamente fora do esperado para a natureza feminina. Convém ressaltar que não se debate aqui a possibilidade de escolher de ter filhos, que sempre foi tratada como um destino comum a qualquer mulher, mas sim a escolha contrária, vinculada à autonomia de controlar seu próprio corpo e futuro.

Essa autonomia se vê limitada em cima de uma ideia de posse sob o corpo da mulher e assim a sociedade segue estabelecendo normas e limites sobre essa dicotomia. Pois, ainda que o espaço privado seja considerado como local natural feminino, a mulher não exerce poder nele, pois é também propriedade do homem. Numa perspectiva de controle, o matrimônio trouxe dentro do código moral burguês que a ideia de uma propriedade que se estende à posse física e até mesmo à personalidade da mulher em relação ao marido. Tal circunstância sendo possível de ser observada como um fator inevitável em qualquer relação, até mesmo as livres de regramentos matrimoniais (KOLONTAI, 2011, p. 51).

Dessa forma, ainda que diante de mudanças sociais e políticas como a entrada da mulher no mercado de trabalho e o alcance de direitos fundamentais previsto diretamente na carta constitucional, a tradição de um papel feminino abstrato a ser seguido determina que ser mulher é um levar em conta os interesses e hierarquias sociais e familiares (KOLONTAI, 2011, p. 53). Essas determinações, incluindo a necessidade de ter filhos e a obrigação de cuidar deles, é parte do que alimenta o sistema econômico capitalista e limita a eficácia dos direitos da personalidade femininos. 
Apesar da tragédia social expressa nos primeiros anos do capitalismo em sua fase industrial, a necessidade premente de manutenção de um cada vez mais extenso exército industrial de reserva fez com que os nascentes Estados-nacionais, ao elaborar suas constituições já na virada do século XIX para XX, instituíssem cláusulas que tornavam crime, passível de punições severas, a prática de interromper voluntariamente uma gestação. Além da criminalização do aborto, eles traziam a consolidação legal moderna da mulher confinada ao espaço privado e sob tutela do homem, seja pai, irmão, esposo ou mesmo o filho (VENTURINI, 2018, p. 02).

Essa postura reforçava a desigualdade de gênero, na qual se estabeleceu uma desvalorização da mulher enquanto personalidade que tem qualidades e defeitos, e que vai além de um acessório de utilidade masculina (KOLONTAI, 2011, p. 54). E no caso da maternidade, uma utilidade meramente voltada a um trabalho reprodutivo.

Essa construção de um modelo simbólico de devoção materna, que se sacrifica totalmente acaba implicando numa desvalorização profissional, política e intelectual, pois parte do pressuposto que a mulher nada é além de um ser voltado a esquecerse e realizar através do casamento e da prole (RAGO, 2014, p. 91). Assim:

[...] a mulher, historicamente, sempre precisou submeter-se à posição de "sem voz", onde seus desejos e vontades foram condicionados aos ditames de uma sociedade patriarcal e conservadora. A importância do gênero feminino resumia-se ao prazer sexual, aos fins reprodutivos e aos afazeres domésticos, distanciando, assim, a mulher de sua inerente característica de ser humano, reduzindo-a a um estágio de "objetificação" (SANTIAGO, 2017, p. 120-121).

Esse estágio de objetificação simbólica sobre o gênero feminino é naturalizado por meio das relações de poder reproduzidas sobre seu corpo e sua sexualidade. Esse controle é de caráter político e pode ser observado no dia-a-dia por meio de julgamentos sociais acerca do comportamento que a mulher tem ou não nos espaços. Discutir esse controle de corpos e da sexualidade no contexto do político e do social é importante para compreender o debate acerca da reprodução, famílias e maternidade, cabendo dentro da realidade atual do Brasil e da América latina onde se desenvolvem posturas conservadoras mesmo após tanta transformação social e conquista de direitos (BIROLI, 2018, p. 135). 
Esse debate se relaciona assim à descriminalização do aborto por livre escolha da mulher como forma de exercício da sua autonomia. Essa recusa remonta a uma violação ao direito ao corpo da mulher e outros direitos decorrentes de ser um indivíduo livre. Uma vez que:

A recusa ao direito ao aborto [...] mantém na legislação concepções diferenciadas de indivíduo e do direito ao próprio corpo, à integridade física e psíquica e à dignidade. $\mathrm{O}$ acesso a esses direitos, quando se criminaliza o aborto, é distinto na letra da lei segundo o sexo dos indivíduos (BIROLI, 2018, p. 139).

Essa concepção diferenciada se comprova enquanto violadora da saúde e da vida feminina. A esse respeito, no Brasil, a Arguição de Descumprimento de Preceito Fundamental nº 54/2012 do Supremo Tribunal Federal (STF), determinou a possibilidade interrupção terapêutica da gestação em fetos anencéfalos. Ocorre que, ainda que no começo do voto o ministro Marco Aurélio tenha se posicionado acerca da não discussão sobre o aborto em um contexto geral, a continuidade do mesmo trouxe fundamentos sobre o direito ao corpo e o direito a uma vida digna da mulher, relacionando-se apenas à gestação em si, não direcionando ao tipo que se referia. Assim, o ministro discorreu:

$\mathrm{O}$ ato de obrigar a mulher a manter a gestação, colocando-a em uma espécie de cárcere privado em seu próprio corpo, desprovida do mínimo essencial de autodeterminação e liberdade, assemelha-se à tortura ou a um sacrifício que não pode ser pedido a qualquer pessoa ou dela exigido" (BRASIL, 2012 p. 78.

Dessa forma, o Estado reconhece que a imposição social para que a mulher continue com uma gestação no seu próprio corpo representa uma violação à sua vida digna e sua autonomia. Em consonância a esse debate teórico e opinativo, o aborto se coloca em dados como uma realidade mortal para a mulher. A Pesquisa Nacional do Aborto de 2016 demonstrou que meio milhão de mulheres recorreram ao aborto em 2015, o que corresponde a 1.300 mulheres por dia, representando quase uma mulher por minuto. Além disso, maioria dos abortos é realizada por mulheres casadas que já têm filhos e a maior parte das mulheres é religiosa - católica ou evangélica (DINIZ et al, 2017). Essa realidade se torna mais gravosa no Brasil, quando se 
considera que nem sempre os dados efetivamente chegam até o Estado, uma vez que:

[...] pesquisas evidenciam a subnotificação das mortes maternas por aborto. No caso dos abortos induzidos, a ilegalidade da prática contribui ainda mais para a subnotificação. Mesmo com a grande dificuldade na identificação do óbito materno por aborto, não foram propostos fatores de correção padronizados específicos para esta causa de óbito [...] (CARDOSO et al, 2020, p. 02).

Assim, o aborto, se for considerado crime, deixa de se atentar para uma realidade de necessário cuidado da saúde da mulher e de defesa do seu direito à vida. A sua criminalização não salva vida de fetos, trata-se apenas de uma ferramenta para morte de mulheres. Logo, sua legalização deve ser vista como bandeira para a todos aqueles que lutam por uma sociedade mais justa, livre e igualitária entre homens e mulheres (VENTURINI, 2018, p. 06)

Tratar sobre a descriminalização do aborto é necessário para enxergá-lo como uma ferramenta de política de saúde da mulher, reduzindo suas mortes e parando de tratar um problema social como crime, forçando uma obrigação em cima de indivíduos já vulneráveis diante da desigualdade de gênero.

\section{DESCRIMINALIZAÇÃO COMO FERRAMENTA DE EFETIVIDADE DA DEMOCRACIA}

Ao enxergar a possibilidade de pensar o aborto enquanto política pública, é preciso falar sobre como essa correspondência se dilui em equilíbrio em uma sociedade e um Estado democrático. Percebemos assim, tal fato social, como forma de atender especificidades e respeitar direitos de diversos grupos não majoritários, como as mulheres.

No que se refere a estar em uma democracia é importante assinalar que ela é parte fundante do Estado brasileiro prevista na Constituição Federal, no seu art. 1ํㅡ, onde tem como formação a dignidade da pessoa humana enquanto seu fundamento. Nas palavras de José Alfonso da Silva:

[...] a dignidade da pessoa humana não é uma criação constitucional, pois ela é um desse conceitos a priori, um dado preexistente a toda 
experiência especulativa, tal como a própria pessoa humana. A Constituição, reconhecendo a sua existência e a sua eminência, transformou-a num valor supremo da ordem jurídica, quando a declara como um dos fundamentos da República Federativa do Brasil constituída em Estado Democrático de Direito (SILVA,1998, p. 91).

A dignidade humana está correlacionada ao direito à igualdade - nesse caso formal - entre homens e mulheres, entre outros direitos fundamentais do art. $5^{\circ}$ do mesmo texto. Uma vez que dentro do Estado democrático as diferenças existem e a convivência entre elas é parte do que compõe uma democracia, saber diluir e aplicar o direito à igualdade entre os indivíduos, para além de uma igualdade formal, isto é, respeitando suas diversidades, é parte do que forma a própria vivência digna.

De forma que o direito à diferença se conecta também ao direito fundamental à cidadania, pois não reconhecer e abraçar as diferenças e especificidades de grupos sociais é lhe negar a própria condição humana (ALVES, 2009, p. 45), incluindo assim a condição de exercício de seus direitos da personalidade.

A partir disso, considerando-se a necessidade de um reconhecimento do grupo mulher, que como já falado não é homogêneo, e seus direitos, é preciso uma postura democrática que abarque as diferentes opressões que podem ou não ser vivenciadas por cada indivíduo simultaneamente. Esse reconhecimento é o que Chantal Mouffe (2013, p. 267) diz ser necessário para abrir margem para uma cidadania dentro do que ela chama de uma democracia radical a qual enfatizará as numerosas relações sociais em que as situações de dominação existem e que devem ser contestadas para que os princípios de liberdade e igualdade sejam aplicados.

Essa ênfase nas relações sociais de dominação se demonstra como necessária para a efetivação de um pluralismo igualitarista, que é:

[...] organizado sob a primazia da igualdade e que conta com diversos atores sociais, inclusive com o Estado, cujos protagonistas constituem subjetividades históricas específicas [e] a proteção a grupos vulneráveis é uma de suas decorrências mais naturais. (ALVES, 2013, p. 127).

Logo, sendo correlacionado a proteção diversidade ao reconhecimento de direitos da personalidade, mostra-se importante ir além de uma homogeneização dos indivíduos para efetivação daquela. Pois, ainda que todos tenham direitos da 
personalidade intrínsecos ao fato de serem seres humanos, o cuidado na proteção daqueles deve ser passado por meio do reconhecimento dos diversos sistemas de opressão e subordinação que cada um está exposto enquanto cidadão.

Fazendo uma relação com o aborto, importa lembrar que, além de enquanto crime ser um fator de causa de muitas mortes de mulheres, esse fenômeno social ainda é um fato passível de ser observado sob as lentes de raça e classe. Ao ser enquadrado enquanto crime, é preciso lembrar que os tratamentos conferidos às mulheres que abortam são diferentes no que concerne à raça (e classe conjuntamente), já que o "aborto [...] penaliza, inegavelmente, as mulheres de baixa renda, que o fazem em condições de precariedade e determinam em grande parte os índices de mortalidade materna existentes no país; (CARNEIRO, 2019, p. 64) e essas mulheres são as negras e pobres. Conforme sinaliza Sueli Carneiro, ao apontar as inúmeras diferenças que recaem sobre essas mulheres na realidade brasileira, é preciso:

[...] reconhecer as diferenças e desigualdades presentes no universo feminino, a despeito da identidade biológica. Dessa forma, as vozes silenciadas e os corpos estigmatizados de mulheres vítimas de outras formas de opressão, além do sexismo, continuaram no silêncio e na invisibilidade (CARNEIRO, 2019, p. 64).

Assim, quando se trata de uma mulher negra, por exemplo, a integridade física está em maior comprometimento, sendo preciso um cuidado ao tratar dos diferentes núcleos de opressão que estão relacionados a ela, já que tal discriminação "não se restringe às políticas do aborto, existe também quando a legislação silencia sobre diferenças e desigualdades que continuam marginalizando grupos da população, deixando assim de agir para reduzi-las ou superá-las" (BIROLI, 2018, p. 139).

Nesse sentido, é importante reconhecer diferenças até mesmo para um efetivo cuidado ao lidar com o tema. Compreender quem são as mulheres brasileiras e quais tipos de direitos e cuidados elas precisam para serem o mais autônomas possível. Para isso é importante o suporte numa nova teorização do direito à diferença, em que se aplique uma política do reconhecimento amparada na promoção de justiça social; separando-se de uma visão puramente assimilacionista, sem deixar prevalecer uma 
cultura - uma raça, um gênero, uma classe - sobre a outra (LIMA; CAPORAL, 2020, p. 23).

Esse formato de construção jurídica, não amparada no reconhecimento de diferenças abre margem assim para a uniformização e aplicação injusta das leis. Numa instância em que todos esses "[...] processos de individuação desiguais e diferenciados não permitem que tratemos dos direitos individuais ou do individualismo como se significassem a mesma coisa para todas as pessoas" (BIROLI, 2018, p. 140). Tais processos de universalização determinam uma uniformidade que conforme apontado por Bauman (1999, p. 45) "alimenta a conformidade e a outra face da conformidade é a intolerância".

Essa mesma intolerância se transforma na incompreensão sobre as escolhas dos sujeitos, nesse caso da mulher, que em conjunto com os sistemas de opressão Ihe retiram a autonomia e não lhe dão acesso efetivo a direitos fundamentais e da personalidade.

Além disso, é importante ressaltar a atuação do Estado como ator social para efetivação de uma cidadania e uma dignidade humana mais igualitária, em especial de gênero, no que corresponde ao controle de corpos a respeito da interrupção de gestação, deveria ser por meio de consideração da mulher como indivíduo autônomo. Isto é, o Estado tem o dever de não interferir nas suas escolhas e na disposição de seu futuro. A esse respeito, é emblemática a decisão tomada na ADPF no 54 do STF, ainda que sendo de tema correlato, porém não direcionado a presente pesquisa ${ }^{6}$. Esclareça-se que, por meio do voto do Ministro Marco Aurélio, a decisão foi categórica ao dizer que:

[...] vale ressaltar caber à mulher, e não ao Estado, sopesar valores e sentimentos de ordem estritamente privada, para deliberar pela interrupção, ou não, da gravidez. Cumpre à mulher, em seu íntimo, no espaço que lhe é reservado - no exercício do direito à privacidade -, sem temor de reprimenda, voltar-se para si mesma, refletir sobre as próprias concepções e avaliar se quer, ou não, levar a gestação adiante. Ao Estado não é dado intrometer-se. Ao Estado compete apenas se desincumbir do dever de informar e prestar apoio médico e

\footnotetext{
${ }^{6} \mathrm{~A}$ decisão apontada refere-se à descriminalização da interrupção terapêutica da gestação de fetos anencéfalos.
} 
psicológico à paciente, antes e depois da decisão, seja ela qual for, o que se mostra viável (BRASIL, 2012, p. 76).

Esse dever de apoio é suplantado pela consideração do aborto enquanto escolha como crime. Nesse sentido, a descriminalização serviria como atenção às especificidades de gênero e como política pública de apoio à mulher. Mas não só isso, ao reconhecer o direito de escolha, o Estado respeitaria as realidades femininas em suas diferentes vivências.

Esse reconhecimento foi possível de ser vislumbrado no acórdão do Habeas Corpus no $124.306 / 2016$ do STF, em que, apesar de não alterar a questão da criminalização do aborto no Brasil, por ser uma decisão voltada para um caso em específico, representou em seu texto os fundamentos que entendem a necessária discussão acerca da proteção dos direitos da mulher nos casos de interrupção da gravidez, permitindo o exercício desse direito - não visto como crime no caso abordado - quando realizado no primeiro trimestre de gravidez.

Nesse sentido, afirmou o Ministro Luís Roberto Barroso (2016, p. 16) que, na situação já difícil de decidir interromper a gravidez, não se faz necessária uma atuação estatal que torne mais difícil a vida da mulher ao ser criminalizada, e complementa pontuando que:

[...] O tratamento penal dado ao tema, no Brasil, pelo Código Penal de 1940, afeta a capacidade de autodeterminação reprodutiva da mulher, ao retirar dela a possibilidade de decidir, sem coerção, sobre a maternidade, sendo obrigada pelo Estado a manter uma gestação indesejada. E mais: prejudica sua saúde reprodutiva, aumentando os índices de mortalidade materna e outras complicações relacionadas à falta de acesso à assistência de saúde adequada. (...) A norma repressiva traduz-se, ainda, em quebra da igualdade de gênero. $A$ igualdade veda a hierarquização dos indivíduos e as desequiparações infundadas, impõe a neutralização das injustiças históricas, econômicas e sociais, bem como o respeito à diferença (BRASIL, $\mathrm{p}$. 19). (grifo nosso).

Seguindo a mesma tônica em seu voto, a Ministra Rosa Weber (2016, p. 33) anunciou a necessidade dessa mudança de paradigma como um reforço dos princípios democráticos, uma vez que o debate deve se dar “(...) a partir dos princípios constitucionais que informam nosso Estado constitucional democrático e, por conseguinte, dos direitos tutelados por este (...)". 
Dessa forma, é possível notar que a retirada do aborto do campo penal e levado até o campo de uma política pública com enfoque na proteção da saúde da mulher e baseada no respeito à sua autonomia representaria uma efetivação do princípio democrático, protegendo e abraçando a dignidade humana para uma maior igualdade de gênero.

\section{CONSIDERAÇÕES FINAIS}

Com o debate apresentado, a perspectiva do presente trabalho foi relacionar a existência digna dos indivíduos a uma dignidade humana sob um olhar de gênero no que se refere ao direito à vida e sua relação com o aborto. Para isso desenvolveu-se o ponto de vista dos direitos da personalidade enquanto aqueles intrínsecos ao ser humano, como necessários de serem considerados no ordenamento para uma maior proteção da dignidade da pessoa humana enquanto princípio basilar do Estado democrático de direito.

A partir disso, observou-se a necessidade de um cuidado na proteção dos direitos da personalidade, em especial nesse trabalho o direito à vida quando se tratar de uma mulher, em virtude das desigualdades e dificuldades no exercício de voz nos espaços.

Esse cuidado foi abordado com mais atenção na segunda sessão dessa pesquisa, ao relacionar o controle social sobre os corpos femininos como forma de manutenção de uma desigualdade de gênero. Tal controle quando coadunado à questão da interrupção de gestão demonstra-se como uma violação aos direitos de autonomia e até mesmo do próprio direito à vida da mulher em virtude do índice altíssimo de mortalidade femininas pós-aborto, conforme se viu, baseado na criação de uma maternidade compulsória imposta em razão do gênero.

Essas imposições são parte do que se reconhece como ausência de reconhecimento das diferentes subjetividades. $E$ que, conforme apontado, se desvincula do que forma a própria democracia. A descriminalização do aborto, com as considerações sobre desigualdade e continuidade de violações à vida da mulher e 
suas expressões corporais, conforme for de sua decisão, deve ser vista como política de defesa do direito da diferenciação.

Dessa forma, caberia ao Estado reconhecer as dificuldades femininas diversas, garantir às mulheres o exercício de sua autonomia, bem como, dar o suporte para proteção da sua saúde e da sua vida. Funcionando assim como um real fortalecedor da democracia e da luta por uma maior igualdade de direitos entre os gêneros. Assim, diante desse cenário, existirá a possibilidade de transmutação da interrupção voluntária da gestação em ferramenta de fortalecimento da própria democracia e de luta por uma maior igualdade de direitos.

\section{REFERÊNCIAS}

ALVES, Fernando de Brito. Constituição e participação popular: a construção histórico-discursiva do conteúdo jurídico-político da democracia como direito fundamental. Curitiba: Juruá, 2013.

ALVES, Fernando de Brito. Para uma fundamentação do direito de minoria em tempos de transição paradigmática. 2009. 126 f. Dissertação (Mestrado) Universidade Estadual do Norte do Paraná: Jacarezinho, 2009.

BADINTER, Elisabeth. Um Amor conquistado: o mito do amor materno; tradução de Waltensir Dutra. Rio de Janeiro: Nova Fronteira, 1985.

BAUMAN, Zygmunt. Globalização: consequências humanas. Tradução Marcus Penchel. (e-book): Editora Zahar, 1999.

BIROLI, Flávia. Gênero e desigualdades: limites da democracia no Brasil. São Paulo: Boitempo, 2018.

BITTAR, Carlos Alberto. Os direitos da personalidade. 8a ed. São Paulo: Saraiva, 2015.

BRASIL, Supremo Tribunal Federal. Arguição de Descumprimento de Preceito Fundamental 54/DF. Relator: Ministro Marco Aurélio, Brasília, 07 de abril de 2012. Disponível em: http://www.stf.jus.br/arquivo/cms/noticianoticiastf/anexo/adpf54.pdf. Acesso em: 15 ago. 2020.

BRASIL, Supremo Tribunal Federal. Habeas Corpus no 124306/RJ. Relator: Ministro Marco Aurélio, Brasília, 09 de agosto de 2016. Disponível em: http://portal.stf.jus.br/processos/downloadPeca.asp?id=311410567\&ext=.pdf. Acesso em: 15 ago. 2020. 
BRASIL. Constituição Federal. Brasília: Senado Federal, 1988. Disponível em: http://www.planalto.gov.br/ccivil_03/Constituicao/Constituiçao.htm. Acesso em: 9 jun. 2020.

BRASIL. Decreto-lei no 2.848, de 7 de dezembro de 1940. Código Penal. Brasil: Congresso Nacional, 1940. Disponível em:

http://www.planalto.gov.br/ccivil_03/decreto-lei/del2848compilado.htm. Acesso em: 10 nov. 2020.

BRASIL. Lei no 10.406, de 10 de janeiro de 2002. Institui o Código Civil. Brasil: Congresso Nacional, 2002. Disponível em:

http://www.planalto.gov.br/ccivil_03/leis/2002/L10406compilada.htm. Acesso em: 10 nov. 2020.

BUTLER. Judith P. Problemas de gênero: feminismo e subversão da identidade. 17ª ed. Rio de Janeiro: Civilização Brasileira, 2019.

CARDOSO, Bruno Baptista; VIEIRA, Fernanda Morena dos Santos Barbeiro;

SARACENI, Valeria. Aborto no Brasil: o que dizem os dados oficiais? Cad. Saúde

Pública, Rio de Janeiro, v. 36, supl. 1, e00188718, 2020. Disponível em:

http://www.scielo.br/scielo.php?script=sci_arttext\&pid=S0102-

311 X2020001305001\&lng=en\&nrm=iso. Access em 10 out. 2020.

CARNEIRO, Sueli. Mulheres em movimento: contribuições do feminismo negro. In: DE HOLLANDA, Heloisa Buarque; NASCIMENTO, Beatriz; GONZALEZ, Lélia; CARNEIRO, Sueli. Interseccionalidades: pioneiras do feminismo negro brasileiro (Pensamento feminista brasileiro), Bazar do Tempo: Edição do Kindle, 2019.

CHUEIRI, Vera Karam de. Constituição radical: uma ideia e uma prática. In: Revista da Faculdade de Direito UFPR, Curitiba, n. 58, p. 25-36, 2013.

CONNELL, Raewyn. Questões de gênero e justiça social. In: Revista de Ciências Sociais, v.4, no 2, p.11-48, jan./jun. 2014.

DINIZ, Débora; MEDEIROS, Marcelo; MADEIRO, Alberto. Pesquisa Nacional do Aborto - 2016, Ciência \& Saúde Coletiva, 2017.

FOUCAULT, Michel. Vigiar e punir: nascimento da prisão. Tradução de Raquel Ramalhete. Petrópolis: Vozes, 1987.

KOLONTAI, Alexandra. A nova mulher e a moral sexual. 2. ed. São Paulo: Expressão popular, 2011.

LIMA, Fernanda; CAPORAL, Angélica Azerego Garcia. Feminismo negro no brasil e luta por reconhecimento: um diálogo com a teoria da justiça de Nancy Fraser. In: 
Revista Eletrônica do Curso de Direito da UFSM, v. 15, n. 01, pp. 01-33, 2020. Disponível em: https://periodicos.ufsm.br/revistadireito/article/view/37166/pdf. Acesso em: 14 jun. 2020.

MARTÍNEZ, Miguel Ángel Alegre; BENDAHÁN, Óscar Mago. Reconocimiento constitucional de la dignidad, individualidad y derechos de la personalidad. In: Revista de Derecho Político, n. 66, pp. 183-234, 2006. Disponível em: http://espacio.uned.es/fez/eserv/bibliuned:Derechopolitico-2006-66-

6B754A1F/reconocimiento.pdf. Acesso em: 09 set. 2020.

MIGUEL, Luis Felipe; BIROLI, Flávia. Feminismo e Política: uma introdução. 1ª ed. - São Paulo: Boitempo, 2014.

MOUFFE, Chantal. Feminismo, cidadania e política democrática radical. In: MIGUEL, Luís Felipe; BIROLI, Flávia. Teoria política feminista: textos centrais. Vinhedo:

Editora Horizonte, 2013, pp. 265-282.

RAGO, Margareth. Do cabaré ao lar: a utopia da cidade disciplinar e a resistência anarquista: Brasil 1890-1930. 4. ed. São Paulo: Paz e Terra, 2014.

ROBERTO, Luciana Mendes Pereira. O direito à vida. In: Scientia luris, v. 7/8, pp. 340-353, 2004. Disponível em:

http://www.uel.br/revistas/uel/index.php/iuris/article/view/11138/9865. Acesso em: 20 out. 2020.

SAFFIOTI, Heleieth I. B. Introdução: a síndrome do pequeno poder. In: AZEVEDO, Maria Amélia; GUERRA, Viviane Nogueira de Azevedo (orgs.). Crianças

vitimizadas: a síndrome do pequeno poder. São Paulo: Iglu editora, 1989, pp. 1321.

SANTIAGO, Brunna Rabelo. Direitos da personalidade e feminismo: o argumento biopolítico da dominação masculina na questão do aborto. In: DIAS, Renato et. al. Gênero, sexualidade e direito II. Florianópolis: CONPEDI, 2017. Disponível em: http://conpedi.danilolr.info/publicacoes/roj0xn13/wu0nu37x/d29L1mDFmRDv3KII.pdf. Acesso em: 14 out. 2020.

SILVA, José Alfonso da. A dignidade da pessoa humana como valor supremo da democracia. In: Revista de Direito Administrativo: Rio de Janeiro, n. 212, p. 89-94, abr./jun., 1998.

SILVA, Nilson Tadeu Reis Campos. Alteridade: a identificação da diferença. In: Revista Direitos Culturais, v. 5, n. 8, pp. 131-166, fev. 2010. Disponível em: http://srvapp2s.urisan.tche.br/seer/index.php/direitosculturais/article/view/361/218. Acesso em: 11 set. 2020. 
VENTURINI, Mariana de Rossi. Aborto: entre o ventre, a propriedade e a produção. 2018. Disponível em: http://www.grabois.org.br/portal/artigos/154540/2018-08-

06/aborto-entre-o-ventre-a-propriedade-e-a-producao. Acesso em: 16 out. 2020. 